\title{
Influencia de los medios de comunicación en el plebiscito por la paz
}

\author{
Influence of the media in the plebiscite for peace in Colombia
}

\author{
Alexander Pinzón Flórez \\ Magíster en Política y Relaciones Internacionales de la Universidad Sergio Arboleda. \\ Docente Investigador Programa de Gobierno y Relaciones Internacionales. \\ Universidad La Gran Colombia. \\ https://orcid.org/0000-0002-0305-5117 \\ jaiber.pinzon@ugc.edu.co
}

Fecha de recepción: agosto de 2020

Fecha de aprobación: dic de 2020

Para citar este artículo / To reference this article Pinzón, A. Influencia de los medios de comunicación en el plebiscito por la paz. Inciso, 22(2);296-315

DOI: http://dx.doi.org/10.18634/incj.22v.2i.1126

\section{Resumen}

Los medios de comunicación, como actores sociales, tuvieron un papel fundamental a la hora de informar durante la campaña por el plebiscito por la Paz celebrado en Colombia en 2016. El presente artículo busca revisar con base en la metodología de Análisis Crítico del Discurso, cómo los medios de comunicación de mayor impacto en el país, en su versión digital, El Tiempo, El Espectador y El Colombiano, construyeron a partir de los editoriales publicados entre el 18 de septiembre y el 1 de octubre de 2016, representaciones sociales particulares de las FARC, y la manera en que estas pudieron haber llegado a influir en la opinión pública de cara a las votaciones plebiscitarias.

Palabras claves: Medios de comunicación, representaciones sociales, FARC, plebiscito en Colombia.

sabilidad. 


\begin{abstract}
The media, as social actors, played a fundamental role in informing during the campaign for the Plebiscite for Peace held in Colombia in 2016. This article seeks to review based on the Critical Discourse Analysis methodology, how the media with the greatest impact in the country, in their digital version, such as El Tiempo, El Espectador and El Colombiano, built from the editorials published between September 18 and October 1, 2016, particular social representations of the FARC, and the way in which they may have influenced public opinion in the face of plebiscite votes.
\end{abstract}

Keywords: Mass media, social representations, FARC, plebiscite in Colombia.

\title{
Introducción
}

El plebiscito celebrado en Colombia en el mes de octubre de 2016 fue un episodio de trascendental importancia para la historia del país en el marco del Proceso de Paz con la guerrilla de las FARC. Gracias a este hecho fue posible la participación de los colombianos en la aprobación o desaprobación de los puntos acordados entre dicha guerrilla y el Gobierno Nacional. El período de campaña por el "Sí” y por el "No" dejó ver con claridad el alto grado de polarización de la sociedad colombiana, no solo frente a los acuerdos con las FARC, sino también frente a las FARC en sí mismas. En ese escenario, los principales medios de comunicación escritos en su versión digital asumieron una postura determinada frente a dicho proceso, y empleando su lugar privilegiado como medios masivos, modelaron y divulgaron una intención de voto frente a la ciudadanía.

El período de campaña en torno al plebiscito se caracterizó por la difusión de ambas posturas en diferentes medios masivos: radio, televisión, prensa tradicional o digital. Cada organización, movimiento, partido político y ciudadano enunciaba sus argumentos a favor o en contra de los Acuerdos de La Habana formando así un cúmulo de información de cara al plebiscito. Sin embargo, dicho cúmulo no se correspondía con la calidad misma de la información. La discusión en torno al Acuerdo y las campañas por el "Sí" y el "No" en el plebiscito se encontraba permeada por visiones muy particulares y sesgadas sobre el proceso de paz en los medios. Los argumentos a favor o en contra del proceso no se presentaron bajo los parámetros esperados de un medio masivo de comunicación como son la imparcialidad o la información concreta y veraz.

Los intereses particulares en torno al plebiscito llevaron consigo a la construcción de determinadas representaciones sobre las FARC, factor empleado en varias ocasiones para generar confianza o desacreditar el proceso de paz. El plebiscito fue pasajero, pero, al ser un momento de gran discusión social, permitió que en los días previos a su realización se manifestaran diversas representaciones que los medios configuraron sobre las FARC y que, finalmente, difundieron a sus lectores a través de sus plataformas digitales. Lo anterior permitió crear un sistema de significados, nominaciones, símbolos e imágenes particulares asociados a las FARC que algunos lectores asumieron como parte de la realidad y como 
aspecto a tener en cuenta a la hora de asumir una postura específica en las votaciones plebiscitarias.

La capacidad de los medios de comunicación para crear imágenes o representaciones de la realidad, en este caso de un actor como las FARC, hace necesaria la reflexión sobre el papel político y social de dichos medios en sociedades como la colombiana, con fenómenos tan complejos y de consecuencias tan nefastas como el conflicto armado interno que se prolongó durante décadas. Y aunque los medios de comunicación y los sondeos de las encuestas realizadas en las semanas previas al plebiscito por la paz en Colombia intentaron precisar unos posibles resultados en las urnas al asumir una postura abierta frente a las votaciones, los resultados finales del plebiscito contravinieron la opinión de los medios de comunicación.

En este escenario es necesario plantearse la siguiente pregunta: ¿hasta qué punto fueron imparciales los medios de comunicación más importantes del país en su versión digital en las representaciones sociales que construyeron sobre las FARC durante el plebiscito por la paz en Colombia en $2016 ?$

Para alcanzar este objetivo, en primer lugar, se realizó una reflexión metodológica sobre el análisis crítico del discurso. En segundo lugar, se abordaron los principales aspectos teóricos que sirvieron como categorías a la luz de las cuales se analizaron los editoriales. En tercer lugar, se hizo una contextualización acerca del plebiscito sobre los acuerdos estableciendo la relación entre los medios de comunicación, el plebiscito y la construcción de representaciones sociales sobre las FARC. Por último, se realizó un análisis crítico del discurso sobre los editoriales escogidos, lo cual permitió responder al objetivo de esta investigación y dar cuenta de las formas de representaciones sociales que construyeron los tres medios acerca de las FARC.

\section{Metodología}

Es pertinente hacer algunas aclaraciones con respecto al alcance de la reflexión que se presentará en este artículo. La primera tiene que ver con la selección de los medios que se analizarán, que en este caso, serán los tres periódicos más leídos en el país. Según el Estudio General de Medios (EGM) de 2015, los periódicos en sus versiones digitales más leídos en Colombia fueron El Tiempo, El Espectador y El Colombiano.

Una segunda aclaración está relacionada con la sección de estos periódicos que se estudió. Martínez y Santamaría (1996) definen el editorial como un "artículo periodístico sin firma que explica, valora y juzga un hecho noticioso de especial importancia. Este juicio colectivo e institucional se formula de acuerdo con una convicción de orden superior que refleja la postura ideológica de cada periódico" (p. 168). Podría entenderse que el editorial tiene una naturaleza política, pues deja de lado la imparcialidad para, en primer lugar, asumir la postura de un sujeto colectivo, despersonalizado, como si se tratara de un miembro o de un representante de la ciudadanía capaz de determinar cuál noticia es prioridad nacional y cuál no. De esta manera, para autores como Ayala (2008) se reconoce la naturaleza del editorial como un mecanismo de dominio, pues para él estos "son la voz del poder" (p. 42) que tiene un rol fundamental en lo que el mismo autor denomina un "sistema de información estratégicamente 
concebido" (p. 337) cuyo fin es persuadir. En segundo lugar, toma los hechos para valorarlos y juzgarlos desde un punto de vista subjetivo buscando convencer. La postura del anterior autor, en palabras de Estrada (2009), permite entender que además de abordar la relación histórica entre medios de opinión y poder político, se sugiere un análisis objetivo y sin odios interpretativos, en donde la naturaleza de los editoriales se concibe ya no como instrumentos de poder político, sino como "el mismo poder político" (p. 325). En tercer lugar, al tratarse de una postura oficial del periódico, la información que se da en otras secciones (por ejemplo, las noticias), estará en ocasiones permeada por esa perspectiva particular. Por estas razones, el editorial representa una forma discursiva interesante para comprender las representaciones que sobre las FARC construyeron los diferentes periódicos y dieron a conocer a la opinión pública dentro de sus posturas frente al acuerdo de paz.

La tercera salvedad metodológica está relacionada con el tiempo. Es mucho lo que los periódicos han escrito sobre las FARC y el plebiscito, pero fue necesario hacer una delimitación temporal que obedeció al hecho histórico en el cual se sitúa este estudio: el plebiscito sobre los acuerdos de paz entre el gobierno de Juan Manuel Santos y la guerrilla FARC-EP. Los días próximos a la votación del plebiscito fueron críticos para que los medios digitales intentaran influenciar a la opinión pública acerca de votar en contra o a favor de los acuerdos. Por esta razón, se tomaron como objeto de estudio los editoriales escritos en versión digital desde el 18 de septiembre hasta el 1 de octubre del año 2016.

Hay un cuarto elemento que deja ver la intencionalidad del editorial y su razón de ser: influir la decisión de los lectores. Hamlet (2009) lo describe más claramente al definir los editoriales como "artículos de diarios o revistas (o muy raras veces piezas de medios audiovisuales) que combinan hechos y opinión para interpretar las noticias y ejercer influencia sobre la opinión pública" (p. 473). El ejercer una influencia sobre quien lee tiene que ver directamente con la formación de representaciones sociales, en este caso sobre las FARC tanto a nivel nacional como internacional.

El análisis de los editoriales no se hizo con el fin de indagar o establecer el grado de veracidad de los hechos que se encontraban en estos. Tampoco se pretendió hacer una medición cuantitativa de la influencia real sobre el voto de los colombianos que pudieron tener ciertos juicios sobre las FARC emitidos por los medios de comunicación. El carácter de esta investigación fue cualitativo, pues el análisis fue inductivo a partir de los editoriales para cumplir con el objetivo de analizar la manera en que cada uno de los periódicos empleó el lenguaje para construir una representación particular sobre las FARC.

El método de investigación escogido para el análisis de los editoriales fue el análisis crítico de discurso. Tal escogencia se debe al carácter masivo de los medios, a su capacidad de ejercer un poder relacionado con la autoridad y el gran alcance de la información, pero además con la capacidad de enunciar, nombrar, de poner rótulos sobre quienes se está escribiendo y, en el caso particular de los editoriales, de hacerlo bajo un manto de anonimato usando la estructura de un texto expositivo-argumentativo para justificar una convicción personal y convencer de ella a los lectores. 
Existe, entonces, una relación de poder implícita en los editoriales. Tal vez la forma de reducir la desigualdad entre quienes leen el editorial y quienes lo producen es develar el mensaje y los lenguajes ocultos. Hacer esto requiere una perspectiva de análisis crítico. Van Dijk (1999) define esta corriente de pensamiento, y a la vez método de las ciencias sociales, de la siguiente manera:

El análisis crítico del discurso es un tipo de investigación analítica sobre el discurso que estudia primariamente el modo en que el abuso de poder social, el dominio y la desigualdad son practicados, reproducidos, y ocasionalmente combatidos, por los textos y el habla en el contexto social y político (p. 23).

En el lenguaje utilizado por los medios de comunicación existen intenciones ocultas que en algunas ocasiones distorsionan la realidad. Esta afirmación parte de reconocer que no tendría sentido escribir un editorial que se presenta ante el público con una convicción personal sin pretender convencer a otros, por lo que el análisis del discurso consiste en esclarecer el fondo de la utilización del lenguaje para, finalmente, dar cuenta de la capacidad que tienen los periódicos de construir una representación particular de las FARC ad portas del plebiscito sobre el Proceso de Paz.

\section{Marco conceptual}

En este apartado se hará un esbozo sobre los elementos conceptuales que permitieron dar cuenta de la relación entre el papel de los medios de comunicación en la sociedad, el uso del lenguaje en los editoriales y la construcción de imágenes o representaciones sobre las FARC en el marco del plebiscito sobre los acuerdos de paz.

Existen diferentes formas de análisis e interpretaciones contemporáneas en torno al campo de estudio de los medios de comunicación relacionados con la edificación de opiniones, juicios, sentidos y significados sociales, especialmente, si se toma en cuenta que interpretación de textos también se debe "realizar un análisis de lo no dicho" (Ayala, 2008, p. 22). El texto Funciones y efectos de los medios de comunicación de masas: los modelos de análisis, escrito por Bretones (1997) es clave para entender este aspecto pues ayuda a comprender el fenómeno que suponen los medios a partir de sus funciones y efectos. La autora identifica cuatro líneas interpretativas que intentan definir a los medios. Para Bretones, una primera línea de interpretación para llegar a comprender la naturaleza de los medios está configurada como elemento de poder político y comercial, pues "los medios de comunicación de masas se perfilan como una función o actividad "manipulativa” (p. 7).

En otras palabras, los medios masivos son utilizados por dirigentes políticos y grandes compañías para hacer que el individuo esté de acuerdo con la conducta e ideales impulsados por estas élites, sea funcional y se someta a los intereses de dichos grupos privilegiados a fin de perpetuar el consumo y la desigualdad en las relaciones de poder. Por otro lado, una siguiente línea para poder definir a los medios se basa en establecer la relación que existe entre los mensajes utilizados y las motivaciones que están alrededor de estos y los sujetos sociales. Es decir, la actuación de los medios como un aparato que filtra la información y genera contenidos que coincidan con lo que busca y sea atractivo para el consumidor, esto, con el propósito de mantener y guiar el orden. 
En un tercer momento interpretativo, según la autora, la función de los medios tiene que ver con el control social, aunque este concepto adquiere dos formas, en esencia, contradictorias. Por una parte, se entiende que el control ejercido por los medios pretende "producir socialmente la escenificación del poder al tiempo que escenifican el "control como resultado" de ese poder" (p. 8), mientras que, por otra parte, se entiende al control no necesariamente en su aspecto coactivo sino, más bien, como una forma de gestión necesaria para las relaciones sociales con el objetivo de organizar de manera coherente las opiniones públicas. En un último momento interpretativo, Bretones considera que el objetivo "de los medios se circunscribe a los papeles reproductivos que estos desempeñan” (p. 9), por lo que a los mismos se les adjudica un papel en aras de la socialización de significados y simbologías culturales.

Otra perspectiva que tiene alguna congruencia con la anterior, al describir el papel de los medios de comunicación en la construcción de representaciones sociales, es la de Manuel Castells (2009) para quien el poder se ejerce mediante la coacción y la construcción de significados. Según lo anterior, es posible decir que los medios de comunicación tienen la capacidad de ejercer poder gracias a que su actividad conlleva a la construcción de significados, lo cual da pie a la segunda categoría de análisis entorno a la representación social.

Para Piñero (2008) las representaciones sociales se definen como una manifestación colectiva e individual de conocimientos en medio de la diversidad de los mismos individuos que componen estas colectividades sociales. Si bien todos los individuos de un grupo identifican y se refieren a un mismo sujeto, objeto o hecho, esto no significa que cada individuo tenga exactamente la misma imagen o representación que los demás sobre el objeto referido. De tal manera que, las representaciones no surgen como consenso, sino que emergen de lo heterogéneo y dejan ver que lo que para un individuo es de una manera, para otro es de otra. También es de resaltar que las representaciones sociales se construyen y transforman continuamente mediante la interacción constante entre las representaciones particulares de cada individuo y el contexto en el que se presentan.

Según Piñero, "las representaciones sociales se expresan en tanto proceso y en tanto contenido" (Piñeros, 2008, p. 6) y este proceso tiene que ver con cómo se adquieren y comunican representaciones y los medios de comunicación están muy ligados con este proceso, pues crean, reproducen y finalmente transmiten "formas simbólicas".

En tanto contenido, "Ias representaciones sociales se manifiestan a través de tres dimensiones: la actitud, la información y el campo de representación" (Piñero, 2008, p. 6). Con la actitud se está haciendo referencia a una apreciación negativa o positiva de lo que se representa. La información está relacionada con el nivel de conocimiento que tiene el individuo sobre el objeto, a partir del cual, lo explica. El campo de representación tiene que ver con la forma como se organizan los elementos anteriores en un núcleo central y unos elementos periféricos. La representación está determinada por las "relaciones que el grupo mantiene con el objeto, así como por el sistema de valores y normas sociales que constituyen el ambiente ideológico del momento y del grupo" (Piñero, 2008, p. 6). La otra parte de la representación son los elementos periféricos o características del contexto histórico particular de cada individuo, las cuales dan a la representación su carácter heterogéneo. Por estar ancladas 
al sistema simbólico y de significados de los individuos, las representaciones tienden a ser estables y resistirse a la transformación y al cambio.

Ahora bien, la importancia de las representaciones sociales, para autores como Ayala (2008), radica cuando el conjunto de sistemas de conocimientos se da para la comprensión de una noticia desde el punto de vista del editorial. Es decir, el papel que juegan los medios de comunicación en la elaboración de representaciones sociales que inciden en la construcción de la opinión pública, es fundamental al tratarse de la materialización de un discurso como forma de control a partir de las mismas representaciones sociales. Según el mismo autor, desde los editoriales se dan lineamientos categóricos de la manera correcta en que se debe actuar y "aquello que se debe creer o no creer" (p. 204). En otras palabras, la influencia de los editoriales radica en que desde esta sección se dice el qué, el cómo y el cuándo de lo que se debe predicar como cierto.

De acuerdo con el interés de esta investigación, el tercer determinante es el que guarda relación directa con los medios de comunicación, pues como lo señalan Hewstone \& Moscovici (1986) los medios masivos como la prensa permiten el intercambio y la difusión de información, de imágenes, representaciones de otros grupos y personas y nociones de la realidad que los individuos terminan integrando al universo de sus saberes.

\section{Contexto histórico de las FARC y el Proceso de Paz (2012-2016)}

Históricamente, la guerrilla de las FARC se definió como "un movimiento revolucionario de carácter político militar nacido en el año de 1964" (Secretariado Nacional de las FARC-EP. (S.f.) párr.1). Desde 1949 se habían empezado a organizar los primeros campesinos afectados por profundas desigualdades sociales y políticas del país generadas por el avance de poderosos latifundistas sobre el campesinado y por el conflicto bipartidista (Molano, 2015, p. 2). Este conflicto se dio entre seguidores del partido conservador y el partido liberal tras el asesinato de Jorge Eliécer Gaitán, período conocido como "La Violencia”, el cual se caracterizó por la utilización de cruentas formas de violencia para eliminar a los seguidores del bando contrario (CNMH, 2014, p.17).

Para el año de 1964 nuevos movimientos políticos empezaban a tener acogida, entre ellos el comunismo, al cual se adhirieron las FARC. La guerrilla comenzó a desarrollarse en zonas del país históricamente abandonadas por el Estado ocupando su papel en los escenarios de la vida cotidiana (CNMH, 2014, p. 30). En 1978, durante la VI Conferencia de las FARC, este grupo propuso "convertirse en una guerrilla nacional, en un "Ejército Revolucionario", y definió que su proyecto era la toma del poder" (CNMH, 2014, p. 17). A partir de ese momento las FARC tuvieron como grupo armado, momentos de auge y debilitamiento, pero no dejaron de ser un actor determinante en la cotidianidad de los colombianos y, por tanto, especialmente presente, en los medios de comunicación durante los 52 años de su existencia como grupo armado al margen de la ley.

Las FARC cometieron diversos delitos como secuestro, extorsión, abuso sexual, desplazamiento forzado, narcotráfico, entre otros. Crecieron a gran escala llegando a representar una seria amenaza para el Estado colombiano que, a su vez, respondió con la fuerza del "Plan Patriota y 
de las políticas de seguridad desplegadas durante el Gobierno de Álvaro Uribe" (CNMH, 2014, p. 271). El desgaste que ha implicado la guerra para ambas partes es la razón por la cual, se han llevado a cabo cuatro intentos de proceso de paz (La Uribe, de Tlaxcala y del Caguán) con distintos gobiernos, incluido este último (el de La Habana), que culminó el 24 de noviembre de 2016 (Gómez, 2017).

El último proceso de paz con las FARC inició con algunas aproximaciones en Río de Oro (Cesar) y con el "encuentro exploratorio" entre el 23 de febrero y el 26 de agosto de 2012 (CNMH, 2014, p. 271). A raíz de este acercamiento el Gobierno y las FARC se pusieron de acuerdo sobre los puntos de la agenda del "Acuerdo General para la Terminación del Conflicto y la Construcción de una Paz Estable y Duradera en Colombia”. La Agenda contempló seis puntos: "desarrollo agrario integral; participación política; fin del conflicto, solución al problema de las drogas ilícitas; víctimas; implementación, verificación y refrendación” (CNMH, 2014, p. 317).

Alrededor de las negociaciones de paz que tuvieron su sede en La Habana, Cuba, se comenzó a generar resistencia de parte de diversos sectores de la política y de la sociedad colombiana, para quienes la salida militar era viable como forma de derrotar a las FARC debido al "impacto del Plan Patriota y otras operaciones de la Fuerza Pública que determinaron el retiro de las FARC a zonas marginales y una importante reducción de su pie de fuerza y poderío militar" (CNMH, 2014, p. 272). A pesar de esto, las FARC se adaptaron a esas nuevas condiciones y reestructuraron su aparato militar (CNMH, 2014, p. 274). De hecho, el "Plan Espada de Honor demuestra que el anunciado fin de las guerrillas no estaba a la vuelta de la esquina” (CNMH, 2014, p. 290).

Las críticas formuladas frente a los acuerdos de paz por parte de la "oposición de importantes personalidades políticas y de algunos columnistas de los medios de comunicación, liderados en buena medida por el expresidente Álvaro Uribe" (CNMH, 2014, p. 325), giraron principalmente en torno a la propiedad de la tierra, la forma de condenar los crímenes, la participación política de las FARC, entre otras. Algunas de estas críticas se basaron en los temores de diversos grupos de poder político y económico que se habían involucrado y beneficiado del conflicto armado interno.

Las críticas permeadas de subjetividad y de temor se convirtieron en mitos no verificables, tales como la idea de que se estaría negociando "la reformulación de prácticamente toda la política pública del Estado (estructura económica y social, reforma a la justicia, relaciones internacionales, etc.)" (CNMH, 2014, p. 317). O que, de firmarse los acuerdos, Colombia se convertiría en una nueva Venezuela refiriéndose a que el comunismo y el sistema de gobierno venezolano (país con el que la guerrilla tenía buenas relaciones) serían instaurados en el país. Así lo expresaba uno de los líderes visibles del "No", el expresidente Álvaro Uribe Vélez (20022010), quien con su política Seguridad Democrática, dio los más duros golpes militares a las FARC:

El Gobierno disimula su indiferencia frente a los anhelos populares con un acuerdo con demagogia agrarista que busca la colectivización del campo y la destrucción del agro productivo. Así empezaron Castro y Chávez, dejaron a sus pueblos sin comida, después destruyeron la industria, la economía toda, ahuyentaron a los empresarios (El Tiempo, 26 de agosto de 2016, párr. 6). 
El Gobierno puso en conocimiento de la opinión pública la existencia de diálogos de paz con las FARC de manera formal "el 4 de septiembre del 2012" (CNMH, 2014, p. 318), y dio inicio a la mesa de conversaciones el 19 de noviembre del mismo año entre los equipos negociadores del Gobierno y de las FARC. Las discusiones en Colombia giraban en torno a los puntos que se irían a negociar y a la participación que se le daría al pueblo en la toma de decisiones sobre lo que se iba a pactar con las FARC. El día 26 de septiembre de 2016, cuatro años después del inicio de las conversaciones, el presidente Juan Manuel Santos en representación del Estado colombiano y Rodrigo Londoño, jefe máximo de las FARC, firmaron el Acuerdo de Paz que puso fin a 52 años de existencia de esa guerrilla (Redacción El Tiempo, 26 de septiembre de 2016, párr. 1). A lo largo de ese período, el país sufrió una fuerte polarización en torno a los mismos acuerdos.

El presidente de Colombia Juan Manuel Santos resolvió que avalar los acuerdos era una responsabilidad de los colombianos, y que dicho aval se conseguiría el domingo 2 de octubre de 2016 (Portafolio, 24 de agosto de 2016) cuando, por medio del plebiscito se formularía la pregunta: “¿Apoya usted el acuerdo final para terminar el conflicto y construir una paz estable y duradera?" (Verdad Abierta, 2016, párr. 4). El plebiscito es un mecanismo de participación ciudadana consagrado en la Constitución, el cual consiste en el pronunciamiento del pueblo que, a través del voto, apoya o rechaza una iniciativa del presidente de la República.

El 31 de agosto iniciaron oficialmente las campañas por el "Sî" y por el "No" frente al plebiscito. Los diferentes partidos políticos, organizaciones y ciudadanos, iniciaron la carrera por convencer a la ciudadanía de aprobar o desaprobar los Acuerdos (Verdad Abierta, 08 de septiembre 2016, párr. 1). El plebiscito se llevó a cabo el día acordado, y con una mayoría de 50, 24\% ganó el "No", frente al 49,76\% de votos por el "Sí" (Semana, 2 de octubre de 2016, párr. 1 y 14). Razón por la cual, los acuerdos no podrían ser implementados. Sin embargo, el presidente Santos conservaba su derecho a seguir negociando y producir un acuerdo de paz diferente, para el cual tenía la libertad de volver a convocar un plebiscito o prescindir de él. Se propuso entonces que el Gobierno se sentara a renegociar, especialmente con el Centro Democrático, principal partido opositor bajo el liderazgo de Uribe Vélez (El Espectador, 4 de octubre de 2016, párr. 2). Así mismo, las FARC ratificaron su disposición a seguir negociando las "cerca de 450 propuestas de "ajuste" al acuerdo suscrito con las FARC" (Redacción El Tiempo, 24 de octubre de 2016, párr. 7).

Finalmente, después de 53 días de haberse llevado a cabo el plebiscito, se firmó el acuerdo de paz reformado, con el cual estuvieron nuevamente en desacuerdo algunos sectores, especialmente el partido Centro Democrático. La refrendación se haría ahora por medio del Congreso, prescindiendo de la figura del plebiscito (El Economista, 23 de noviembre de 2016, párr. 1).

\section{Análisis del discurso de los editoriales de El tiempo, El espectador y El colombiano en su versión digital}

El periódico El Colombiano (2016) hizo un esfuerzo considerable por presentarse ante los lectores como un diario de carácter imparcial días antes de concretarse una de las coyunturas históricas más importantes en el país: el plebiscito, situación reflejada en una de sus 
redacciones autoproclamadas "escrupulosamente equilibradas en la información" titulada "Dos semanas para elevar el debate" (18 de septiembre de 2016). No obstante, la opinión que divulgó sobre las FARC tuvo una fuerte inclinación hacia la reactivación de los recuerdos sobre la guerra en los colombianos. Ejemplo de lo anterior fue el editorial del 20 de septiembre titulado "FARC: el perdón como política". Allí el editorial cuestionó el motivo de la Décima Conferencia de las FARC llevada a cabo el 16 de septiembre del mismo año, cumbre en la que se hablaría de la aprobación interna de los acuerdos de paz y de posteriores estrategias para la participación del grupo guerrillero en política:

(...) sobre la "cumbre", debería estar la determinación de convertir el pedido de perdón en parte de los planes con los que pretenden participar en la vida política de la nación.

Sí, el perdón. En cada uno de los casos en que se establezca la responsabilidad de los subversivos en secuestros, reclutamientos forzados, torturas, violaciones, desapariciones, masacres, ejecuciones extrajudiciales y demás asesinatos. (...) ofrecer disculpas por tantas ofensas a la humanidad (20 de septiembre de 2020, párr. 2-3).

Además de recalcar los actos lesivos cometidos por las FARC, el fragmento muestra que el escritor busca llamar la atención sobre el perdón, haciendo ver que este es un aspecto olvidado y poco importante para la guerrilla. La imagen que comienza a construir este editorial es la de un grupo que en realidad no estaba arrepentido, poco le importan las personas a las que dañaron y su único interés fue integrarse al escenario político del país.

Otro de los aspectos que llama la atención en este editorial es la mezcla entre argumento y juicio de valor. En primer lugar, el escritor escoge una definición de política asociada a la moral, como se lee en el siguiente apartado: “(...) se entiende la política como una rama de la moral que se ocupa de la actividad, en virtud de la cual una sociedad libre, compuesta por personas libres, resuelve los problemas que le plantea su convivencia colectiva", esto con el fin de apelar a argumentos ad hominem, pues complementa "no es solo desde la misericordia cristiana y de la ética humana que se plantea este reto a las FARC. Es desde el ejercicio mismo de una política que no acolite todas las formas de lucha" (El Colombiano, 20 de septiembre de 2016).

Pedir perdón se muestra como un reto para las FARC que, al entenderse como propio de personas con ética y creyentes en la cristiandad, deja a los integrantes del grupo guerrillero como no cristianos y sin ética. Se genera así la imagen de no pertenencia de las FARC a la nación (pues la mayoría de la población colombiana sí es cristiana) y se reaviva la división entre un "nosotros" y un "ellos"; la distinción "amigo" / "enemigo" de la que Carl Schmitt habló, seguirá vigente, esta vez no en el marco de un conflicto armado, sino en la política definida por Foucault como "continuación de la guerra por otros medios" (2000, p. 29). Finalmente, el escritor de El Colombiano remata el editorial con una afirmación que directamente podría poner a pensar a los ciudadanos en votar por el "No" en el Plebiscito: "así mismo, la sociedad colombiana no puede renunciar a esperar que las FARC empiecen su vida legal con dos gestos muy políticos: la verdad y el perdón" (El Colombiano, 20 de septiembre 2016, párr. 4).

Este apartado recuerda uno de los argumentos más potentes de los sectores políticos que se oponían a la aprobación de los acuerdos. Para estos grupos las FARC no debían participar de 
la vida civil y política del país sin antes haber respondido por sus crímenes, alegaban que esta garantía de verdad y perdón no estaba incluida en los acuerdos y por tanto el plebiscito no debería aprobarse. Esto dejaba a las FARC como sujeto de desconfianza.

Comentarios como el primero que refuerza los hechos victimizantes y los sentires de la ciudadanía relacionados con estos, fueron retomados en otros de sus editoriales titulado "FARC cierran capítulo de violencia", en donde, por un lado, referencias como "quedan grabadas en la memoria - no sepultadas en el olvido - las cientos de horas de terror y sangre que las FARC le provocaron al país con su "guerra irregular" y desprovista de cualquier consideración frente al Derecho Internacional Humanitario" (25 de septiembre de 2016, párr. 4) y otras referencias como "escuchar a "Timoleón Jiménez" disertar sobre la ética que impulsó sus acciones y el significado humanístico de sus principios inspiradores no resiste el más mínimo examen frente a los crímenes cometidos y a la relación histórica de las atrocidades sufridas" en el editorial titulado "FARC, en terrenos de la democracia" ( 27 de septiembre de 2016, párr. 4), son algunas muestras del esfuerzo del periódico por rememorar los males que se atribuye a las FARC en el país, dificultando que sus lectores asumieran una actitud más resiliente hacia este grupo, el conflicto y el plebiscito.

Acerca de la divulgación de estos relatos surgen dos comentarios. El primero, contribuye a materializar, en términos discursivos y comunicativos, la relación existente entre los medios de comunicación y la memoria colectiva de la violencia en Colombia. La memoria de la violencia, y la construcción sociocultural son susceptibles de convertirse en plataforma de lucha por la imposición de significados respecto a acontecimientos desastrosos ocurridos en el pasado.

Esta situación lleva a que los ejercicios de memoria estén atravesados inevitablemente por diferentes flujos ideológicos de información funcionales a grupos de poder determinados dentro del proceso comunicativo. Esta afirmación se basa en los planteamientos de autores como Mateus (2009) quien, al estudiar a los medios de comunicación y su influencia en la identidad colectiva de las víctimas del municipio de Quinchía, Risaralda, concluye que:

La información transmitida en los medios influye en la memoria que las personas tienen acerca de los hechos que afectan a los diversos grupos, en este caso en la percepción que las víctimas tienen de ellas mismas y del señalamiento al que se han visto sometidas (p. 5).

Desde esta perspectiva es importante reiterar que los medios de comunicación poseen un papel fundamental en la edificación de aquella memoria sobre el conflicto y, por ende, en la toma de decisiones frente al plebiscito, pues son los responsables de construir y divulgar un conjunto de símbolos, significados y juicios que acompañan la narrativa de la violencia. En el discurso de El Colombiano, se obtuvieron dos grandes resultados. El primero de ellos consistió en que, reiterar la crueldad de la guerra, tuvo como fin evitar el olvido y, a raíz de esto, promover que la sociedad exigiera ciertas garantías de no repetición como condición para aprobar el plebiscito. Sin embargo, se hizo mención sencillamente de lo terrible que fueron esos hechos y no se hacía referencia a hechos concretos de violencia, con información exacta que permitiera una construcción seria y consciente de memoria. El segundo resultado, es que en los editoriales se advierte cierta fascinación y exaltación de la guerra que "opaca la paz" con lo cual se construye toda una agenda temática sobre la violencia en el plano de lo público 
que "privilegia el drama, la tragedia, la novedad, la espectacularidad, el antagonismo y el heroísmo" (Bonilla y Tamayo, 2007, p. 28).

Lo anterior esboza la tensión existente entre la memoria y el olvido que plantean los medios de comunicación. Mucho se ha debatido sobre el tema, pero aquí sería clave citar el trabajo de Delgado y Jaramillo (2011) quienes, al indagar sobre el deber de la memoria y las razones del olvido, se preguntan:

¿Cómo configurar unas políticas hacia el futuro que sirvan para que no se repita el horror? Tanto las razones filosóficas como las alternativas políticas en torno a ella se debaten en una "delgada cuerda" entre quienes defienden, no sin razón, un "deber de memoria" a favor de las víctimas y quienes aceptan, incluso demandan y razonan, sobre la importancia de ciertas cuotas de olvido a favor de los victimarios y de la nación (p. 130).

En El Colombiano hay un claro rechazo sobre esas "cuotas de olvido" (en lo que tiene que ver con los diferentes adjetivos sobre las FARC, no sobre los hechos en sí), cuotas que de alguna manera requirió el Gobierno de Juan Manuel Santos para la aprobación e implementación de los acuerdos de paz, situación que añadió más tensión al reconocimiento de la responsabilidad de los victimarios. El Colombiano otorgó un privilegio enunciativo para los horrores de la guerra en detrimento de otros factores que también hicieron parte del conflicto como, por ejemplo, los elementos políticos e ideológicos que acompañaron a la guerra en sí misma.

Estas narrativas e imágenes a las que se hace referencia no son otra cosa que "realidades parcializadas" o, en palabras de Lippmann (citado en Rubio, 2009), ficciones que no siempre se basan en argumentos lógicos y en hechos específicos, pero sobre las cuales se asienta la opinión pública, por lo que los medios de comunicación son un mecanismo fundamental de administración de los recuerdos que guían los juicios, sensaciones y percepciones que constituyen los imaginarios sociales de los ciudadanos. La construcción estereotipada hecha sobre las FARC como un grupo violento por parte del periódico, no merecedor de ningún tipo de aprobación moral, posiblemente contribuyó a materializar un escepticismo sobre el Acuerdo y su relevancia futura.

Para poner de relieve la heterogeneidad en las perspectivas de estos tres medios de comunicación, se trae a colación un editorial de El Espectador que va más allá de recordarle al lector las atrocidades de las FARC. Sus mensajes ponen sobre la mesa la necesidad del diálogo y la oportunidad que brindaba el aqcuerdo para la construcción de paz en Colombia. Son varios los ejemplos; sin embargo, resulta interesante recalcar uno en particular, el editorial publicado en la víspera del plebiscito titulado "Es momento de decir sí":

Apostar con el Sí por la implementación de este Acuerdo es abrir una puerta de nuevas posibilidades para que esta nación adolorida pueda comenzar a cicatrizar sus heridas y construir una sociedad diferente, más justa, más incluyente y en la que, sobre todo, la vida recupere el valor que perdió al paso del conflicto (...) no podemos esquivar en este momento trascendental para el futuro del país la responsabilidad de tomar partido por el Sí a los Acuerdos con las FARC, que entendemos como una oportunidad histórica para señalarle un nuevo rumbo a Colombia (...) No seamos inferiores a la oportunidad que este Acuerdo nos ofrece. ¿Por qué no ensayamos la paz? (1 de octubre de 2016, párr. 1-8). 
Resulta evidente que quien escribió este editorial abiertamente intentó, no solo sembrar en el lector una opinión favorable sobre el proceso de paz, sino que además intentó hacerlo apelando a las emociones, a la esperanza y al anhelo de la paz, para la cual, la aprobación del plebiscito sería la única oportunidad, la oportunidad histórica de alcanzarla. La ciudadanía debía estar a la altura, pues era una muestra de que la sociedad en general apuntaba a objetivos comunes más elevados que el de la guerra o la venganza. Casi la totalidad de este editorial trata de justificar por qué el hecho de que El Espectador tome partido, en este caso por el Sí, no atenta contra la democracia ni la imparcialidad del periódico. Razón por la cual emplea un argumento de autoridad al referirse a lo que hubiera pensado el célebre exdirector del periódico, Guillermo Cano:

Es cierto que hay puntos particulares de estos Acuerdos que generan dudas y que vistos individualmente resultan intolerables, pero no tenemos duda alguna de que el equipo negociador y el norte que le trazó el presidente de la República estuvo allí tomando cada decisión con el bien de la patria como principio tutelar, y que lo que consiguió acordar con el enemigo es ni más ni menos lo que se podía alcanzar (...) no estamos traicionando aquella posición de neutralidad que prometió Guillermo Cano frente a los procesos democráticos. Mucho menos estamos traicionando sus valores en la lucha contra el crimen y, en particular, contra el narcotráfico, que sabemos ha sido fuente de lucro criminal para las Farc (1 de octubre de 2016, párr. 5-7).

No se le quitaba la valoración negativa a las FARC, las nominaba como enemigo y mencionaba su vinculación con el narcotráfico, enunciaba que la oportunidad de paz que brindaban los acuerdos de La Habana era fruto del trabajo del Gobierno Nacional, con lo que no reconocía gestos de buena voluntad por parte de las FARC, reforzando la dicotomía entre lo legal y lo ilegal. Sin embargo, al hablar de las heridas y de la pérdida de valor de la vida, el editorial no afirmaba que hubiese sido consecuencia de las acciones de las FARC únicamente, sino que se refería al "conflicto" como responsable, reconociendo que hubo causas estructurales y que otros actores también eran responsables. En esa misma línea se encontraba el editorial titulado "Las razones de un sí", del diario El Tiempo del 2 de octubre, que invitaba con desparpajo a votar por el Sí y señalaba con claridad la deuda social del Estado como uno de los responsables del conflicto armado en Colombia:

EL TIEMPO recomienda a sus lectores que acudan hoy a las urnas la opción del Sí en el tarjetón. Esta postura nace del convencimiento de que el acuerdo con las FARC no solo es una oportunidad única para llevar una confrontación de las balas al plano de los argumentos, sino que tiene, como también ya lo afirmamos, "el potencial de corregir fallas estructurales del pacto que da sentido a esta sociedad" (...) vemos en sus páginas una hoja de ruta que, virtuosamente recorrida, logrará saldar la deuda social del Estado con vastos sectores de la población por décadas excluidos, sin que ello signifique volver a barajar en términos de modelo económico actual (2 de octubre de 2016, párr. 1-7).

El Tiempo utilizó una línea argumental a favor de la aprobación de los acuerdos en el plebiscito, basado en la tensión entre la moderación (al mostrar que el acuerdo no era perfecto, que habría desafíos y que este no buscaba cambiar el modelo económico hacia el comunismo) y la expectativa por la oportunidad futura, no solamente de superar el conflicto, sino de reestructurar la constitución al referirse al "pacto que da sentido a esta sociedad". Un 
ejercicio de nominación positiva se da cuando el escritor deja de referirse a los miembros de las FARC como tal. En su lugar, prefiere nombrarlos como actores aislados del uso de las armas situándolos en un escenario político y como miembros de la sociedad civil:

Este argumento, el de estar por fin ante una oportunidad concreta y real de pasar esta cruel página de la insurgencia armada, es una razón valiosa entre las que invitan a respaldar con el voto lo firmado el lunes por Juan Manuel Santos y Rodrigo Londoño (2 de octubre de 2016, párr. $5)$.

Ya no se refería a él como "Timochenko", sino que usaba su nombre civil Rodrigo Londoño. En adelante, se haría referencia a otros apelativos como "la insurgencia" o "negociadores" los cuales contribuyeron a disminuir la visión dicotómica de amigo/enemigo que se mencionó párrafos atrás. Una coincidencia entre este editorial y los de El Espectador y EI Colombiano, tiene que ver con el uso de conceptos como argumento. En El Colombiano se recurría al concepto de política en un sentido moral, mientras que en El Espectador y El Tiempo se hablaba de la democracia apelando a la "madurez" frente a la aceptación de que existían "visiones diferentes", madurez que es responsabilidad de la ciudadanía alcanzar. El siguiente fragmento les llama la atención a los lectores sobre su rol. Ya no aparece como único responsable las FARC o el Estado. Aquí el argumento consistía en que se debía incluir a las FARC en la vida política ya que ese gesto demostraba que la sociedad colombiana es democrática y civilizada:

(...) es deseable que la asistencia hoy a los puestos de votación sea masiva. Y es que este paso (...) debe ser mucho más que un acuerdo entre representantes del Estado y la insurgencia, y además una prueba -sorteada con éxito, como esperamos- de nuestra madurez democrática. Esto, en el sentido de demostrar que interpretamos el tener visiones diferentes sobre cuál ha de ser el rumbo de la sociedad como algo positivo (2 de octubre de 2016, párr. 2-3).

El Tiempo, al igual que El Colombiano, utilizó como argumento el temor, ya no hacia la falta de garantías de no repetición, sino por la incertidumbre sobre los rumbos que tomaría el país de obtenerse un voto negativo mayoritario en el plebiscito:

Y es pertinente referirnos al contraste entre lo minucioso y esperanzador de la senda trazada $-\mathrm{y}$ que deberá seguirse de resultar ganador el Sí (por supuesto, no ajena a riesgos) - y el nivel de incertidumbre que se genera de darse el desenlace opuesto (2 de octubre de 2016, párr. 8).

Por el contrario, un aspecto que marca la diferencia entre El Tiempo y El Colombiano, es el lugar que le fue dado a las víctimas. Para El Tiempo, las víctimas y sus necesidades sí han sido prioridad, y este hecho fue un argumento para "motivar más" el voto por el Sí en el plebiscito. Más adelante en el mismo fragmento, se rescató la postura según la cual el trato que debían recibir los victimarios no había de ser únicamente el castigo, buscando aplacar los ánimos de venganza e indignación de la opinión pública frente a la reincorporación de las FARC a la vida civil y política:

El hecho de que la negociación -y esto se refleja en el texto final- haya tenido a las víctimas como centro, gracias a lo cual podrán acceder a la verdad, a la reparación y a la certeza de la no repetición, debería también motivar más (...) las heridas que deja abierta la guerra hay que 
ayudar a sanarlas y de que para ello es un requisito que la justicia brinde algo más que castigos a los victimarios (2 de octubre de 2016, párr. 6).

Uno de los argumentos más potentes para votar por el Sí fue el hecho de que los colombianos dejen de morir por causa del conflicto. El Tiempo se refería a "razones sólidas para creer" sin mencionar cuáles y dejaba que los lectores viesen en las FARC sujetos en los que era posible confiar:

Como los propios negociadores lo han dicho en numerosas ocasiones, se trata de un acuerdo imperfecto, pero pensamos que han dado razones sólidas para creer que es, como también han afirmado, el mejor posible. Y, sobre todo, uno llamado a salvar miles de vidas (2 de octubre de 2016, párr. 6).

Los editoriales de los tres periódicos coincidían en varios aspectos. En todos existía un esfuerzo explícito por influir en las decisiones del electorado sobre el plebiscito a partir de la construcción de juicios de valor, de la generación de emociones y expectativas sobre los Acuerdos y sobre las FARC, más que de traer a colación hechos reales y concretos sobre los cuales los lectores pudieran fundamentar una reflexión libre y consciente. Como pudo demostrarse anteriormente en el análisis crítico del discurso sobre los editoriales de los diarios seleccionados, la estructura argumentativa fue casi la misma, pero con una gran diferencia: dos de ellos, El Tiempo y El Espectador, se referían a las FARC de una manera más positiva que El Colombiano.

Se identificó que el recurso lingüístico de la nominación estuvo presente en todos los editoriales. La nominación, entendida como el "conjunto de rasgos definitorios de las identidades de los grupos que abren paso a la comprensión crítica de las representaciones propuestas por la prensa y su papel en la construcción de un fenómeno social" (Pardo, 2005, p. 169) ayuda por tanto a crear, promover, transformar y eliminar diversas formas de comprender e interpretar las relaciones sociales (Van Dijk, 1999) y la realidad en la que están inmersas.

\section{Consideraciones finales}

En los editoriales de El Colombiano se contribuyó a formar una imagen en la cual las FARC aparecían como actores que generaban desconfianza, al reactivar los recuerdos sobre la guerra en los colombianos y la posibilidad de considerarlos como ciudadanos insertados en las dinámicas institucionales resultaba inconcebible. Esto es así no solo por las acciones pasadas, sino porque se cuestiona que los miembros del grupo guerrillero fueran personas iguales al resto de ciudadanos colombianos cuando se mencionó que son incapaces de pedir perdón precisamente porque hacerlo exige tener ética y una estructura de valores cristiana.

Se trata, como se mencionó en el análisis del discurso anterior, de argumentos ad hominem a raíz de los cuales se obtuvo la imagen de un grupo que en realidad no estaba arrepentido de los daños causados y cuyo único interés era integrarse al escenario político del país. Los aspectos a los que apeló quien escribía la sección editorial, estuvieron relacionados finalmente con que las FARC no pertenecían a la nación, reforzando la peligrosa distinción "amigo" / "enemigo", a partir de la cual se alcanza a deshumanizar en algún grado a los miembros 
de este grupo guerrillero y, por consiguiente, se generalizaba la idea de excluirlos e, incluso, exterminarlos. La narrativa de desconfianza y deshumanización finalmente llevó a asumir una actitud poco resiliente frente a las personas reinsertadas.

En cuanto a El Espectador, la narrativa actuó en defensa del Gobierno Nacional como guía de los acuerdos, con lo que se le quitaba importancia al papel de las FARC. El escritor justificó que estar a favor de los acuerdos de paz no equivalía a estarlo con las FARC ni a dejar de lado la imparcialidad. Por esa razón, y por el peso de la imagen de Guillermo Cano, quien escribió los editoriales tuvo que seguir mostrando a las FARC como enemigos a pesar de ser partidario del plebiscito. De hecho, se refería a ellos como "el enemigo" y trae a colación su vinculación con el narcotráfico, prefiere no emitir de manera clara y directa juicios de valor, pero no le quita la valoración negativa a las FARC.

Al recordar que Cano fue asesinado por el narcotráfico con el que las FARC se habían financiado, la disertación de El Espectador pudo coincidir con la discusión interna que cada colombiano debió enfrentar: votar "No" al plebiscito como si se tratara de las mismas FARC, o desligar una cuestión de la otra y seguir valorando negativamente a las FARC, pero dando una oportunidad al país. La imagen pública de las FARC que se construyó desde El Tiempo estuvo caracterizada por un reconocimiento de que la guerrilla no fue la única responsable del conflicto, pues se señala con claridad la deuda del Estado con algunos sectores sociales, e incluso va más allá al considerar válida la necesidad de realizar cambios a la Constitución. Así mismo, la manera en cómo las nominaba tenía un matiz político al dejar de referirse a "Timochenko", y en vez de ello usar el nombre civil de Rodrigo Londoño. Al resto los describía como "la insurgencia" o los "negociadores".

Aparte de estas referencias, los editoriales de El Tiempo adoptaron un carácter defensivo de la buena voluntad de las FARC, al resaltar que para el proceso en general, las víctimas siempre fueron tenidas en cuenta y que a los guerrilleros se les debía dar un trato que fuese más allá del castigo. La representación final estaba orientada a generar confianza en la sociedad frente al plebiscito y las FARC. De un lado, se tienen dos periódicos que intentan opacar la versión más negativa y conflictiva sobre las FARC y, de otro lado, se tiene un periódico que posee un discurso moralizador que mantenía en la memoria de los colombianos las tragedias provocadas por la guerrilla.

A través de las características que conforman las representaciones vistas, se evidencia el papel, actor discursivo y de poder de los medios de comunicación (Ayala, 2008), quienes logran, a través de sus discursos, nominar explícita o tácitamente; asignar características a actores sociales determinados; objetivar la cultura y los fenómenos de una sociedad; crear formas de representar el mundo "poniendo en evidencia estructuras, reglas y valores que dan cuenta del orden social en el que se aspira a legitimar lo expresado" (Pardo, 2005, pp. 169-170). Lo anterior contribuye a instalar esas nominaciones y esas representaciones en la memoria de los individuos, donde se relacionarán con los conocimientos y emociones previas asociadas a las FARC, reforzándolas o transformándolas.

Las referencias tácitas o indirectas y la omisión o presentación de información poco específica sobre hechos y actores como el Estado, los grandes grupos empresariales o los paramilitares 
en casi todos los editoriales, generan desconocimiento de la realidad y de los actores a los cuales se les comienza a identificar de una manera borrosa (Pardo, 2005, p. 195). Esta perspectiva reduce la capacidad de comprender la realidad en toda su complejidad, pues se establecen polos opuestos que dejan por fuera hechos puntuales para comprender lo sucedido.

Sobre las FARC también recayó cierto nivel de invisibilización que consistió en nominarlos como grupo la mayoría de las veces. Lo anterior facilita que los medios y las personas pongan etiquetas y emitan juicios con gran facilidad, reduciéndose la capacidad de descripción y verificación de estas proposiciones. Para Ayala (2008), los mismos medios de comunicación se valen de la memoria pública para profundizar en dicho imaginario colectivo de una manera determinada (en el caso de este artículo, negativo respecto de las representaciones sociales que se construyeron en torno a las FARC) que, de una u otra forma, ellos mismos (los medios) han construido dentro de un contexto de poder.

Este aspecto es especialmente grave teniendo en cuenta que en torno a las FARC ya existían emociones negativas que, promovidas por los periódicos, predispusieron a los individuos en el modo de interpretar a este actor social y sus acciones. De tal modo que, se pudieran truncar la formulación de salidas viables, perpetuando y fortaleciendo las posturas radicales que, históricamente, en el país han desencadenado los diferentes periodos de violencia. En este sentido amplio se establece la responsabilidad social de la prensa en la construcción de conocimiento fiable y con la construcción de país.

Se invita a pensar al lector y a quienes crean productos comunicativos de alcance masivo, sobre la complejidad de los procesos comunicativos en los medios. Los individuos y sus realidades son vulnerables ya que los contenidos de los medios de comunicación, en apariencia "neutrales", son en realidad dispositivos que juegan un papel activo y fundamental en la edificación de fenómenos de vital importancia como la imagen, los significados y los juicios.

Por último, más allá de los análisis de discursos, se hace urgente y necesario para sociedades como la colombiana, con fenómenos sociales tan complejos como el conflicto armado, identificar cómo, por qué y para qué los medios masivos de comunicación crean representaciones sociales particulares sobre actores y la realidad en general, por lo que se invita a la realización de estudios más amplios con el objetivo de enriquecer las discusiones y grados de comprensión en este tema, especialmente en la toma de decisiones de carácter político como lo fue el plebiscito por la paz en 2016.

\section{Referencias bibliográficas}

Ayala, C. (2008). Exclusión, discriminación y abuso de poder en El Tiempo del Frente Nacional: una aproximación desde el análisis crítico del discurso (ACD). Bogotá: Universidad Nacional de Colombia.

Bonilla, J., Tamayo, C. (2007). Violencia en los medios, los medios en las violencias. Recuperado de: http://www.javeriana.edu.co/redicom/documents/ Lasviolenciasenlosmedios.pdf 
Bretones, M. (1997). Funciones y efectos de los medios de comunicación de masas: los modelos de análisis. Universitat de Barcelona. Recuperado de: http://diposit.ub.edu/ dspace/bitstream/2445/6201/1/FUNCIONES\%20Y\%20EFECTOS\%20DE\%20LOS\%20 MEDIOS\%20DE\%20COMUNICACI\%C3\%93N\%20DE\%20MASAS.\%20\%20Bretones.pdf

Castell, M. (2009). Comunicación y poder. Alianza Editorial: Madrid.

Centeno 0. (2014). Discursos públicos y construcción de ciudadanía: ¿poder de los medios de comunicación? Orbis, Revista Científica Ciencias Humanas, vol.10, No. 28, Fundación Miguel Unamuno y Jugo. Maracaibo, Venezuela, págs. 120-133. Disponible en: http:// www.redalyc.org/articulo.oa?id=70930408007

Centro Nacional de Memoria Histórica. (2014). Guerrilla y población civil. Trayectoria de las FARC 1949-2013. Tercera edición. Bogotá: CNMH. Recuperado de: http://www. centrodememoriahistorica.gov.co/descargas/informes2013/farc/guerrilla- poblacioncivil.pdf

Delgado, M., Jaramillo, J. (2011). “Deber de memoria” y “Razones de olvido" en la justicia transaccional colombiana. Revistas Unal. 24. (71). 129-147. Recuperado de: https:// revistas.unal.edu.co/index.php/anpol/article/view/44243/45538

El Colombiano. (18 de septiembre de 2016). Dos semanas para elevar el debate. Recuperado de: http://www.elcolombiano.com/opinion/editoriales/dos-semanas-para-elevar-eldebate- HG4998797

El Colombiano. (20 de septiembre de 2016). Farc: el perdón como política. Recuperado de: http://www.elcolombiano.com/opinion/editoriales/farc-el-perdon-como-politicaYF5016199

El Colombiano. (25 de septiembre de 2016). Farc cierran capítulo de violencia. Recuperado de: http://www.elcolombiano.com/opinion/editoriales/farc-cierran-capitulo-deviolencia- KY5045963

El Colombiano. (27 de septiembre de 2016). Farc, en terrenos de la democracia. Recuperado de: http://www.elcolombiano.com/opinion/editoriales/farc-en-terrenos-de-lademocracia- BK5059289

El Economista. (23 de noviembre de 2016). Oposición colombiana rechaza acuerdo de paz; rompe diálogo con Santos. Recuperado de: www.eleconomista.com.mx/ internacionales/Oposicion-colombiana-rechaza-acuerdo-de- paz-rompe-dialogo-conSantos-20161123-0064.html

El Espectador. (1 de octubre de 2016). Es momento de decir sí. Recuperado de: https://www. elespectador.com/opinion/editorial/momento-de-decir-si-articulo-657974

El Espectador. (4 de octubre de 2016). Hora de escuchar a la oposición. Recuperado de: www.elespectador.com/noticias/paz/hora-de-escuchar- oposicion-articulo-658344 
El Tiempo. (26 de agosto de 2016). “Con argumentos haremos austera campaña al 'No' al plebiscito": Uribe. Recuperado de: http://www.eltiempo.com/colombia/otras- ciudades/ posicion-de-uribe-frente-a-acuerdo-de-paz-con-las-farc-50265

El Tiempo. (26 de septiembre 2016). Santos y ‘Timochenko' firmaron histórico acuerdo de paz. Recuperado de: http://www.eltiempo.com/politica/proceso-de-paz/ceremonia- dela-firma-de-la-paz-en-colombia-en-vivo-33953

El Tiempo. (24 de octubre de 2016). Gobierno refuerza equipo para nuevo acuerdo con Farc. Recuperado de: http://www.eltiempo.com/politica/proceso-de-paz/equipo-pararenegociar-acuerdo-de-paz-con-las-farc-40543

Estrada, F. (2009). César Augusto Ayala Diago. Exclusión, discriminación y abuso de poder en El Tiempo del Frente Nacional: una aproximación desde el análisis crítico del discurso (ACD). Anuario colombiano de historia social y de cultura, Vol. 36, No. 1, pp. 321-325. Bogotá: Universidad Externado de Colombia.

Foucault, M. (2000). Defender la sociedad, Curso en el Collège de France (1975-1976). Argentina: Fondo de cultura económica.

Gómez, G. (18 de noviembre de 2017). Así está Colombia, un año después de las Farc. El Tiempo. Recuperado de: http://www.eltiempo.com/politica/proceso-de-paz/efectos-encolombia-tras-un-ano-de-la-firma-del-acuerdo-de-paz-con-las-farc-152740

Hamlet, J. (2009), Editorials Inc C. H. Sterling (Ed). Encyclopedia of journalism (p. 473- 477). Thousand Oaks, CA, USA: SAGE

Hewstone, M., Moscovici, S. (1986). De la ciencia al sentido común. En Moscovici, S. (Comp.), Psicología Social, II. Pensamiento y vida social. Psicología social y problemas sociales, 679-710. España: Paidós.

Ibáñez, T. (1994). Representaciones sociales. Teoría y método. En Psicología social construccionista, 153-216. México: Universidad de Guadalajara.

Martínez, J., Santamaría L. (1996). Manual de estilo (2a ed.). Indianapolis, IN, USA: Instituto de Prensa de la Sociedad Interamericana de Prensa.

Mateus, A. (2009). Medios de Comunicación y su influencia en la identidad social de las víctimas. Estudio de caso: La detención masiva en el Municipio de Quinchía. (Tesis de Pregrado). Universidad Colegio Mayor de Nuestra Señora del Rosario. Bogotá, Colombia. Recuperado de: http://repository.urosario. edu.co/bitstream/handle/10336/1270/52818164.pdf;jsessionid=E2 B7BA185488316FC7408DA76C6555E2?sequence=1

Molano. A. (2015). Fragmentos de la historia del conflicto armado (1920-2010). Espacio crítico. Recuperado de: http://www.altocomisionadoparalapaz.gov. $\mathrm{co} /$ mesadeconversaciones/PDF/fragmentos-de- la-historia-del-conflicto-arma do-1920-2010-1447167631-1460380435.pdf 
Moscovici, S. (1979). El psicoanálisis, su imagen y su público. Argentina: Ed. Huemul.

Pardo, A. (2005). Representación de los actores armados en conflicto en la prensa colombiana. FORMA Y FUNCIÓN 18, páginas 167-196. Departamento de Lingüística, Facultad de Ciencias Humanas, Universidad Nacional de Colombia, Bogotá, D.C. Recuperado de: http://www.redalyc.org/articulo.oa?id=21901807

Piñero S. (2008), La teoría de las representaciones sociales y la perspectiva de Pierre Bourdieu: Una articulación conceptual. CPU-e, Revista de Investigación Educativa Disponible en: http://www.redalyc.org/articulo.oa?id=283121713002

Portafolio. (24 de agosto de 2016). El plebiscito por la paz será el domingo 2 de octubre. Recuperado de: http://www.portafolio.co/economia/gobierno/plebiscito-por-la- pazsera-el-de-octubre-de-2016-499850

Rubio, J. (2009). Opinión pública y medios de comunicación. Teoría de la agenda setting.

Gazeta de Antropología. 25. (1). Recuperado de: http://www.ugr.es/ pwlac/ G25_01JoseMaria_Rubio_Ferreres.pdf

Secretariado Nacional de las FARC-EP. (S.f.). Quiénes somos y por qué luchamos. Recuperado de: www.farc-ep.co/nosotros.html

Semana. (2 de octubre de 2016). Atención: Gana el No en el plebiscito para la paz. Recuperado de: http://www.semana.com/nacion/articulo/plebiscito-para-la-paz-ganael-no- en-las-votaciones/496486

Van Dijk, T. (1999). El análisis crítico del discurso. Anthropos. (186). 23-36. Recuperado de http://www.discursos.org/oldarticles/El\%20an\%E1lisis\%20cr\%EDtico\%20del\%20 discurso.pdf

Verdad Abierta. (02 de octubre de 2016). Plebiscito: lo que pasa cuando un acuerdo de paz se decide en las urnas. Recuperado de: http://www.verdadabierta.com/procesos-depaz/farc/6430-plebiscito-lo-que-pasa-cuando- un-acuerdo-de-paz-se-decide-en-lasurnas

Verdad Abierta. (08 de septiembre de 2016). La arena política del Plebiscito. Recuperado de: http://www.verdadabierta.com/procesos-de-paz/farc/6395-la-arena- politica-delplebiscito 